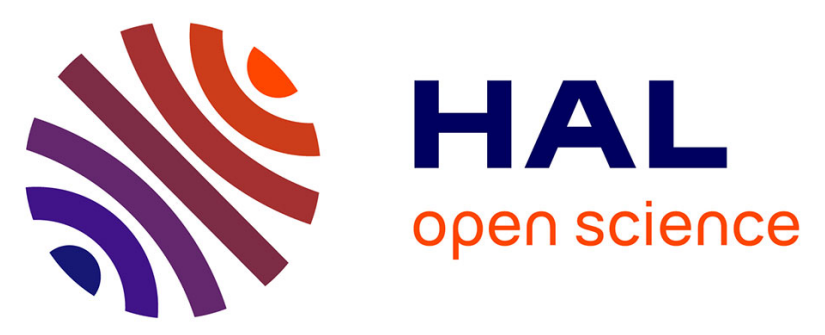

\title{
Applying Gamification for Developing Formal Knowledge Models: Challenges and Requirements
}

Jannicke Baalsrud Hauge, Stefan Wiesner, Ioana A. Stefan, Antoniu Stefan, Klaus-Dieter Thoben

\section{- To cite this version:}

Jannicke Baalsrud Hauge, Stefan Wiesner, Ioana A. Stefan, Antoniu Stefan, Klaus-Dieter Thoben. Applying Gamification for Developing Formal Knowledge Models: Challenges and Requirements. IFIP International Conference on Advances in Production Management Systems (APMS), Sep 2016, Iguassu Falls, Brazil. pp.713-720, 10.1007/978-3-319-51133-7_84 . hal-01615794

\author{
HAL Id: hal-01615794 \\ https://hal.inria.fr/hal-01615794
}

Submitted on 12 Oct 2017

HAL is a multi-disciplinary open access archive for the deposit and dissemination of scientific research documents, whether they are published or not. The documents may come from teaching and research institutions in France or abroad, or from public or private research centers.
L'archive ouverte pluridisciplinaire HAL, est destinée au dépôt et à la diffusion de documents scientifiques de niveau recherche, publiés ou non, émanant des établissements d'enseignement et de recherche français ou étrangers, des laboratoires publics ou privés.

\section{(ㄷ)(i)}

Distributed under a Creative Commons Attribution| 4.0 International License 


\title{
Applying Gamification for Developing Formal Knowledge Models: Challenges and Requirements
}

\author{
Jannicke Baalsrud Hauge ${ }^{1,2}$, Stefan Wiesner ${ }^{1}$, Ioana A. Stefan ${ }^{3}$, Antoniu Stefan ${ }^{3}$, \\ Klaus-Dieter Thoben ${ }^{1,4}$ \\ ${ }^{1}$ BIBA - Bremer Institut für Produktion und Logistik GmbH at the University of Bremen, \\ Bremen, Germany \\ \{baa, wie, tho\} @biba.uni-bremen. de \\ ${ }^{2}$ KTH Royal Insitute of Technology, Flemingsberg, Sweden \\ ${ }^{3}$ Advanced Technology Systems Targoviste, Romania \\ ${ }^{4}$ Faculty of Production Engineering, University of Bremen, Bremen, Germany \\ \{ioana.stanescu, antoniu.stefan\}@ats.com.ro
}

\begin{abstract}
A main challenge in developing formal knowledge models is to efficiently elicit knowledge from various resources and form a coherent body of knowledge that can be validated and extended by user communities. The higher the complexity of a system, the more challenging it is to establish these models, specifically if there are several stakeholders involved, with various level of knowledge and needs. The usage of participatory design approaches in combination with Serious Games (SG) could ensure that all stakeholders are active, as well as that each perspective can be considered. So far manufacturing concepts have not reached their full potential due to the fact that gamification efforts are costly, time consuming to develop, and require the constant involvement of developers even for small changes. The authors discuss the use of a gamification tool to support knowledge processes, respectively knowledge experiencing, conceptualizing, analyzing and applying in engineering environments. To support this approach, especially in terms of costs, the paper presents an approach that makes customization accessible for non-SG professionals.
\end{abstract}

Keywords: Gamification · Knowledge capturing · Product Service System

\section{Introduction}

Nowadays, the field of systems engineering is influenced by rapid technological change and ever growing competition. In order to be the first to react on market trends, methodologies like concurrent engineering (CE) are introduced to shorten development cycles and reduce "time to market" [1,2]. However, just being fast is not sufficient; additionally, the system has to be both appropriate and cost effective [3]. Customers demand integrated solutions and services, covering the whole system life cycle, from ideation to decommission, thus more and more companies are evolving their business activities to form product-service-systems. These systems are complex and dynamic and their

adfa, p. 1, 2011.

(C) Springer-Verlag Berlin Heidelberg 2011 
requirements evolve in time. The already existing knowledge (either on existing products, and services or just related to the ideas never brought to the market) is often distributed among employees, and different departments in an organization do often have different requirements.

Requirements define the needs of organizations, groups, or people along with their surroundings, and describe what a solution must offer in order to satisfy those needs. Their formulation, documentation and maintenance are the main objectives of requirements engineering (RE). It describes "a process, in which the needs of one or many stakeholders and their environment are determined to find the solution for a specific problem" [8]. Inadequate RE is one of the main sources for the failure of development projects and culminates in exceeding budgets, missing functionalities or even the abortion of the project $[9,10]$. For complex systems this requires that the knowledge within the organisation can be captured and transferred. Within complex systems, as well as for product development, participatory or co-creative design approaches are often used in order to involve stakeholders in the decision-making process at early stage in order to ensure that the developed system is in line with their needs. The same approaches can also be used in order to capture the knowledge existing in the organisation, but it requires that there is a tool that is able to capture the knowledge, as well as involving the right people. This might also lead to a better usage of resources. From a technical point of view this integration can be realized today focusing on reusability of components [9] as well as through better collaboration across different process steps [10].

The required competencies for system development and support in other life cycle phases are included through collaboration with partners from different domains [4]. This increases both the number of stakeholders involved in systems engineering and the complexity of the system itself. Consequently, understanding what the customer and the other affected stakeholders expect from the system, i.e. their underlying needs, and linking information from all phases of the life cycle to the development process is a prerequisite for successful systems engineering [5-7]. This represents however a challenge, since much of the knowledge is not formalized and unstructured, thus difficult to retrieve and process.

Previous work $[11,12]$ has highlighted that sustainable adaptation and integration of game design elements into engineering systems can be a good approach for both increasing the process innovation as well as to help collecting information from complex processes. However, [11] also show that further analysis of the enabling mechanisms as well as on how to capture the knowledge are needed. A more detailed analysis of the challenges shows that accommodation of gamification concepts, mechanics and components into engineering systems implies substantial modifications of these systems. A key is here the development of the knowledge models. One of the main challenges in developing formal knowledge models is to efficiently elicit knowledge from distributed resources and form a coherent body of knowledge that can be validated and extended by user communities.

This paper builds upon the perspective where gamification supports knowledge processes using a participatory and gamified approach for complex engineering processes like the requirement engineering of PSS. 


\section{Methodology}

The methodological approach is based on combination of research methods. A literature review was carried out targeting gamification, knowledge processes, and information on engineering applications like PSS and supporting technologies. Scientific papers were accessed through Scopus searching for associated key words [13]

The relevance of the downloaded papers for this article was based on assessing the abstract, as well as by searching for the combination of gamification and mechanisms in the full papers. The first search based on abstracts followed by a refined search. As several expressions are used in literature to describe the PSS concept, we applied TITLE-ABS-KEY ("product-service" OR PSS OR IPS OR "Extended Product") as the first search term, combined with AND TITLE-ABS-KEY ("knowledge management" OR "knowledge sharing") as the second term. This resulted in 214 identified abstract and the refine search identified 40 articles. The search related to gamification of engineering applications was carried out using the ("ENGINEERING APPLICATION" AND ("GAMIFICATION" OR "SERIOUS GAMES" OR "SIMULATION".)). This resulted in 369 abstracts. Adding the same key words as in the definition search resulted in only identifying 15 articles that could be considered of being relevant.

The work with the specific engineering applications and the gamification had a different methodical approach. The researchers have been involved in the specifications and development of the scenarios. Design Science was the overall scientific approach in this work $[14,15]$, so action research was applied [16].

\section{Characteristics of a PSS}

In order to capture the knowledge needed for a RE approach for PSS, it is necessary to identify the specific characteristics of such systems. In the following, some widely used definitions of PSS found in the literature are analyzed for these characteristics.

"A Product Service system (PS system) is a marketable set of products and services capable of jointly fulfilling a user's need. The PS system is provided by either a single company or by an alliance of companies. It can enclose products (or just one) plus additional services. It can enclose a service plus an additional product. And product and service can be equally important for the function fulfilment. The researcher's need and aim determine the level of hierarchy, system boundaries and the system element's relations" [17] .

"A PSS is an integrated product and service offering that delivers value in use. A PSS offers the opportunity to decouple economic success from material consumption and hence reduce the environmental impact of economic activity. The PSS logic is premised on utilizing the knowledge of the designer-manufacturer to both increase value as an output and decrease material and other costs as an input to a system" [18] .

"An Industrial Product-Service System is characterized by the integrated and mutually determined planning, development, provision and use of product and service shares including its immanent software components in Business-to-Business applications and represents a knowledge-intensive socio-technical system'.... 
IPS ${ }^{2}$ enable innovative function-, availability- or result-oriented business models" [19].

The analysis of the above definitions reveals some characteristics that seem to be specific for PSS in general. These characteristics are listed below:

- Integration of product and service shares, including software components;

- Mutual planning, development, provision and use of product and service shares;

- Fulfilling an end user need by delivering value in use;

- Provided by either a single company or by an alliance of companies;

- Dynamic adoption of changing customer demands and provider abilities;

- Enabling innovative function-, availability- or result-oriented business models.

The characteristics shows the complexity of PSS, thus defining the requirements and the system specification are challenging. The next section therefore looks at how a participatory design approach can be used for supporting the challenging task

\section{$4 \quad$ Participatory Design Approach}

Knowledge capturing remains a compelling case for organizations, especially because knowledge is a dynamic asset that continually must be updated, revised, and built on to maintain a valid base 20 and value. Furthermore, it is a challenge that a lot of the information is not formalized, and thus it is difficult to capture with current tools. To address this challenge, the authors have considered key knowledge-centric drivers that apply to organizations, regardless of their industry 21.

- The failure of organizations to know what they already know;

- The emergent need for smart knowledge distribution;

- Knowledge velocity.

- The issue of knowledge walkouts and high dependence on tacit knowledge.

- The need to deal with knowledge-hoarding propensity among employees.

- A need for systemic unlearning.

Highly interconnected systems like smart manufacturing systems need to be explained and managed across many layers - technological, social, data, human and institutional [24]. Further, in the absence of suitable analytical and formal tools, institutions within complex systems take decision based on heuristics. Such heuristics contain significant knowledge both about the stakeholders' perspectives on the systems and on their management strategies. These heuristics needs to be collected in some form to overcome limitations and embed local institutional knowledge in formal tools. This implies that the development of these models and tools should be done in a participatory manner, to ensure all stakeholders collectively develop and reach an understanding of the model. Such participatory methods, in conjunction with these complex models and tools also support model validation. Simulation Gaming provides ways to collectively decide on the problem formulation, system boundaries and on the dynamics of the system that will be addressed. 
By implementing adaptable and customizable gamified SMEs that support knowledge management, the organization will be able to plan and implement activities that stimulate employee interest and participation 20, and that enables them to benefit of a wide range of opportunities. The challenge in the knowledge capturing part of PSS and manufacturing application is that much of the information is not formalized and not structured. The next section discusses under which circumstances gamification of an application can support the knowledge gathering and improve the knowledge model.

\section{$5 \quad$ Gamification of Manufacturing Environments: Requirements on Concept and Challenges}

Gamification consists of using game-based elements and mechanisms in non-game environments with the purpose of employing the motivational properties of games [26]. Gamification as a method has be criticized, and there are some drawbacks like the manipulation aspect [27]. A simple addition of gamifying elements does not automatically translate into the desired outcomes, so gamification components and elements need to be designed and adapted to the context they are applied to. To do so, it is necessary to establish clear goals, incremental goals and rewards, mechanisms of progression, intermediary and final statuses, etc.

Another key challenge concerns the actual incorporation of gamification processes into existing application, which is a complex task even for experienced developers. Integration of gamification mechanisms carried out by manufacturing environments' developers can answer to some of the above-mentioned issues. However, these environments do not fully benefit of the potential of gamification mechanisms, as identified by Wood [26], if such systems do not allow tutors/ users customize their working environments. Users are not actively involved in the SMEs architecture and this limits their capabilities and abilities to perform better. Moreover, the emergence of new technologies requires new approaches and more flexible solutions for integration, empowering users to customize.

Based on the consideration above, a gamified manufacturing environment that aims at capturing, process and feed a formal model need to have the following characteristics:

- Recognition and reward systems for outstanding individual contributions at a project or the organization level.

- Examples and best practices can be extracted from tracked gameplay.

- Recurring challenges that employees are experiencing can be identified and addressed.

- Contextual knowledge reuse is automatically supported, and knowledge transfer can potentially impact all PSS users.

- Exploit the added value of social knowledge through a gamified approach that enables people to discover and share knowledge.

- Access to personalized working environments is enabled.

We are currently working on the gamification of engineering process for knowledge capturing. The gamification is realized in Unity. It mirrors the main 
processes for future PSS system. It is designed as a gamification of the requirements elicitation process. Even though it uses role playing mechanisms, each player plays they normal position in the company. The example below explains one of three case studies where we have carried out the beta testing, so still in progress.

In the given example, the task is to decide which requirements future PSS need to fulfil within the manufacturing of office furniture. In this example the 3D model of the office of the service providers was important into the Unity engine directly. In a second step a narrative story line, describing the main steps of the requirements elicitation process was added and game elements like time restriction and rewards were applied. The gamification is facilitated and uses creativity methods like adapted versions of six thinking hats etc.

The beta test was carried out Mid-June 2016 with 6 different participants covering all the involved stakeholders' groups. It was set up as a workshop of $2 \times 2 \mathrm{~h}$. The first initial results showed that the gamification of the environment helped in analyzing the existing requirements (collected using a traditional method) from different perspectives and to refine these. These first set of stakeholder requirements were related to

- Support for collaboration between the stakeholder

- Business models for servitisation

- Measurement and assessment of brand value and sales bids

- Integration of technologies like sensor and

- Feedback integration either via data analytics or customer/employee

- Interface design

For the more concrete applications (i.e. how to integrate sensors and how to use data for a new service), the gamification supported the process sufficiently according to the participants, and the collected outcome regarding capturing more details of the system was achieved. However, the current gamification showed some weaknesses related to the support on more abstract requirements like future business models. The gamification clearly showed some limitations here, so that it we did not capture much of the participants' knowledge here in one of the group. In the second group, this worked better. Why this problem occurred needs further investigation.

\section{Conclusion}

The paper describes the challenges of generating a formal modal and capture knowledge in a simulation game built using previously developed tools. The authors discuss the characteristics of PSSs and the participatory design approach, with the purpose of supporting the implementation of gamification mechanisms in manufacturing environments.

Technology reshapes the world we learn, work, and live in. New levels of interaction between men and machine have become possible and more widespread, opening the way towards reliable, sustainable, technology-driven ecosystems.

The growth, maturation, and widespread adoption of technologies have the potential to disrupt and innovate, and offers new opportunities for data collection and retrieval. This paper discusses the current challenges of PSS and the potential of gamification to 
enhance knowledge processes and user interface in PSS. Present and future scenarios are presented to reflect how gamification can impact current and future systems of systems. The concept of a gamification tool is introduced as a mean to streamline knowledge processes and enable PSS tutors/ users to directly adapt and personalize PSS to better answer their needs

Future work will explore the integration of digital gams into PSS, exploring key challenges in terms of standardization and interoperability, as well as advances in hardware and software to discover new opportunities for enhancing user experiences and outcomes.

Acknowledgements. This work has been funded by the European Commission through the Projects PSYMBIOSYS: Product-Service sYMBIOtic SYStems (No. 636804) and BEACONING (No. 687676). The authors wish to acknowledge the Commission and all the project partners for their contribution.

\section{References}

1. Corsetti, A., Ribeiro, E. A., Garbi, G. P., Zanta, K., Medeiros, M., Loureiro, G.: Complex Systems Developed with System Concurrent Engineering. In Concurrent Engineering Approaches for Sustainable Product Development in a Multi-Disciplinary Environment (pp. 1057-1068). Springer London (2013)

2. Chang, W., Yan, W., Chen, C. H.: Customer Requirements Elicitation and Management for Product Conceptualization. In Concurrent Engineering Approaches for Sustainable Product Development in a Multi-Disciplinary Environment (pp. 957-968). Springer London (2013)

3. Kossiakoff, A., Sweet, W. N., Seymour, S., Biemer, S. M.: Systems engineering principles and practice (Vol. 83). John Wiley \& Sons (2011)

4. Blanchard, B. S.: System Engineering Management (Vol. 64). John Wiley \& Sons (2012)

5. Sage, A. P., Rouse, W. B.: Handbook of Systems Engineering and Management. John Wiley \& Sons (2011)

6. Elgh, F.: Modelling and Management of Manufacturing Requirements in Design Automation Systems. In Complex Systems Concurrent Engineering (pp. 321-328). Springer London (2007)

7. Nilsson, P., Fagerström, B.: Managing Stakeholder Requirements in a Product Modelling System. Computers in Industry, 57(2), 167-177 (2006)

8. Nuseibeh, B., Easterbrook, S.: Requirements Engineering: A Roadmap. In: Proceedings of the Conference on the Future of Software Engineering, Limerick (2000)

9. Hauksdóttir, D., Mortensen, N. H., Nielsen, P. E.: Identification of a Reusable Requirements Structure for Embedded Products in a Dynamic Market Environment. Computers in Industry, 64(4), 351-362 (2013)

10. Boehm, B.; Basili, B.: Software Defect Reduction Top 10 List. IEEE Computer, 34(1), IEEE Computer Society, Los Alamitos, 135-137 (2001)

11. Kosmadoudi, Z., Lim, T., Ritchie, J., Liu, Y., Sung, R., Baalsrud Hauge, J., Garbaya, S., Wendirch, R., Stanescu, I.A.: Harmonizing Interoperability - Emergent serious gaming in playful stochastic CAD environments. Games and Learning Alliance - Second International Conference, GALA 2013. Springer International Publishing, 390-399 (2013) 
12. Hesmer, A., Hribernik, K.; Baalsrud Hauge, J.; Thoben, K-D.: Supporting the Ideation Processes by a Collaborative Online Based Toolset. International Journal of Technology Management 55(3/4): 218-225 (2011)

13. Kitchenham, B., et al.: Systematic literature reviews in software engineering, A systematic literature review. Information and Software Technology, 51(1), p. 7-15 (2009)

14. Kuechler, B. and V. Vaishnavi, Promoting relevance in IS research: an informing system for design science research. Informing Science: The International Journal of an Emerging Transdiscipline, 14(1), 125-138 (2011)

15. Pries-Heje, J., R. Baskerville, and J.R.: Venable, Strategies for design science research evaluation (2008)

16. Sein, M.K., et al.: Action Design Research. MIS Quarterly, 35(1), 37-56, (2011)

17. Goedkoop, M. J.: Product service systems, ecological and economic basics. [The Hague], Zoetermeer: [Ministry of Housing, Spatial Planning and the Environment, Communications Directorate]; Distributiecentrum (1999)

18. Baines, T. S., Lightfoot, H. W., Evans, S., Neely, A., Greenough, R., Peppard, J. et al.: Stateof-the-art in product-service systems. In Proceedings of the Institution of Mechanical Engineers, Part B: Journal of Engineering Manufacture, 221(10), 1543-1552 (2007)

19. Meier, H.; Roy, R., Seliger, G.: Industrial Product-Service Systems-IPS2. In CIRP Annals - Manufacturing Technology 59 (2), 607-627 (2010)

20. Atwood, C. G., Knowledge Management Basics.: American Society for Training \& Development, Danvers. (2009)

21. Tiwana, A.: Knowledge Management Toolkit. Pretince Hall (2000)

22. Uden, L., Eardley, A.: Innovative Knowledge Management. IGI Global (2010)

23. Loh, A. E., Lim, L. K., Ahmed, P. K.: Learning Through Knowledge Management. Routledge (2013)

24. Palfrey, J. G., Gasser, U.: Interop: The Promise and Perils of Highly Interconnected Systems. Basic Books (2012)

25. Girard, J., Girard, J. P.: Social Knowledge. IGI Global, Hershey. (2010)

26. Wood, L. C., Reiners, T.: Gamification. In Khosrow-Pour, M. (Ed.) Encyclopedia of Information Science and Technology, Third Edition. IGI Global (2014)

27. Kapp, K., M.: The Gamification of Learning and Instruction Fieldbook: Ideas into Practice. Pfeiffer, San Francisco (2013) 